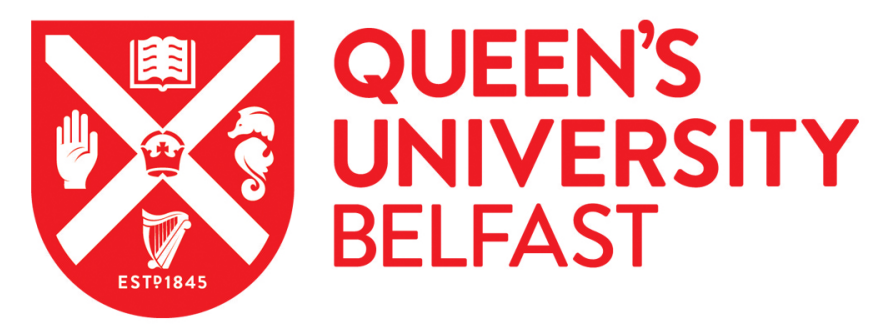

\title{
Non-invasive structural and metabolic retinal markers of disease activity in non-proliferative diabetic retinopathy
}

\author{
Weisner, G., Blindbæk, S. L., Tang, F. Y., Cheung, C. Y., Henriksen, J. E., Stefánsson, E., Peto, T., \& \\ Grauslund, J. (2021). Non-invasive structural and metabolic retinal markers of disease activity in non- \\ proliferative diabetic retinopathy. Acta Ophthalmologica. https://doi.org/10.1111/aos.14761
}

Published in:

Acta Ophthalmologica

Document Version:

Peer reviewed version

Queen's University Belfast - Research Portal:

Link to publication record in Queen's University Belfast Research Portal

Publisher rights

Copyright 2021 Acta Ophthalmologica Scandinavica Foundation. Published by John Wiley \& Sons Ltd.

This work is made available online in accordance with the publisher's policies. Please refer to any applicable terms of use of the publisher.

\section{General rights}

Copyright for the publications made accessible via the Queen's University Belfast Research Portal is retained by the author(s) and / or other copyright owners and it is a condition of accessing these publications that users recognise and abide by the legal requirements associated with these rights.

Take down policy

The Research Portal is Queen's institutional repository that provides access to Queen's research output. Every effort has been made to ensure that content in the Research Portal does not infringe any person's rights, or applicable UK laws. If you discover content in the Research Portal that you believe breaches copyright or violates any law, please contact openaccess@qub.ac.uk. 


\section{Title}

Non-invasive structural and metabolic retinal markers of disease activity in non-proliferative diabetic retinopathy

\section{Authors}

Gwen Weisner 1, 2,3,4

Søren Leer Blindbæk ${ }^{1,2}$

Fang Yao Tang 5

Carol Y Cheung 5

Jan Erik Henriksen 2, 6

Einar Stefánsson 7,8

Tunde Peto ${ }^{2,3}$

Jakob Grauslund 1,2,6

\section{Affiliations}

1. Department of Ophthalmology, Odense University Hospital, Odense, Denmark

2. Department of Clinical Research, University of Southern Denmark, Odense, Denmark

3. Centre for Public Health, Queen's University Belfast, Belfast, UK

4. OPEN, Open Patient data Explorative Network, Odense University Hospital, Odense, Denmark

5. Department of Ophthalmology and Visual Sciences, The Chinese University of Hong Kong, Hong Kong, China

6. Steno Diabetes Center Odense, Odense University Hospital, Odense, Denmark

7. University of Iceland, Reykjavik, Iceland

8. Landspitali University Hospital, Reykjavik, Iceland

\section{Corresponding author}

Professor Jakob Grauslund, MD, PhD, DMSci

Department of Ophthalmology

Odense University Hospital

Sdr. Boulevard 29

DK-5000 Odense C, Denmark

Phone: +452127 1877

E-mail: jakob.grauslund@rsyd.dk 


\begin{abstract}
Purpose:

Metabolic and structural microvascular retinal alterations are essential components in diabetic retinopathy (DR). The present study aimed to measure changes at different stages of non-proliferative DR (NPDR) and to explore interactions of imaging-based metrics.
\end{abstract}

\title{
Methods:
}

This cross-sectional, cohort study included 139 eyes from 80 diabetic patients. Each patient underwent dilated fundal examinations including colour fundus photography, retinal oximetry, and optical coherence tomography angiography (OCTA), analysed by semi-automated and automated software. DRseverity was classified according to the International Clinical Diabetic Retinopathy (ICDR) Severity Scale, ranging from no DR to severe NPDR (level 0-3). Retinal metabolism was evaluated by oximetry as retinal arteriolar $\left(\mathrm{raSatO}_{2}\right)$ and venular oxygen saturation $\left(\mathrm{rvSatO}_{2}\right)$, and macular microvascular structure was measured by OCTA as the area of foveal avascular zone (FAZ), vessel density (VD), vessel diameter index (VDI), FAZ circularity, and fractal dimension (FD) in the superficial and deep retinal capillary plexus.

\section{Results:}

A trend for increasing $\mathrm{rvSatO}_{2}$ was found with increasing DR-severity $(51.3 \%, 53.3 \%, 54.2 \%, 59.8 \%$, $\mathrm{p}=0.02$ ). Increasing severity of DR associated with decreasing FD in the superficial and deep plexus ( $p<0.001$ and $p=0.014)$, and in the superficial plexus decreasing VD $(p<0.001)$, increasing VDI $(p=0.003)$, and decreasing FAZ circularity $(\mathrm{p}=0.006)$. A few interactions were identified between $\mathrm{raSatO}_{2}, \mathrm{rvSatO}_{2}$ and VDI, but only in the deep capillary plexus ( $\mathrm{p}<0.01$ and $\mathrm{p}<0.01$ ).

\section{Conclusion:}

Alterations of the venular retinal vascular oxygen saturation and microvascular structural abnormities were found continuously throughout the DR-spectrum. Given the sparse correlations between metabolic and structural abnormalities, it seems that these occur independently in DR.

\section{Key Words}

Diabetic retinopathy, non-proliferative diabetic retinopathy, diabetes, optical coherence tomography angiography, retinal oximetry 


\section{Introduction}

Diabetic retinopathy (DR) is the most common complication in diabetes and one of the leading causes of blindness in the working-age population of developed countries (Prokofyeva \& Zrenner 2012). As a way to prevent vision loss, regular eye screening by retinal fundus photography is a cost-effective (Peters et al. 1993) and valid method (Liesenfeld et al. 2000). Eye screening aims to identify sightthreatening DR, like proliferative diabetic retinopathy (PDR) and diabetic maculopathy, prior to irreversible visual loss. Many patients are examined annually regardless of disease activity, even though individualized screening intervals may save resources (Aspelund et al. 2011). In order to identify patients at risk of disease progression, multiple risk factors that may be related to DR progression, such as duration of DM, hyperglycaemia and hypertension were identified in previous studies. However, they are insufficient to explain the risk of DR progression (1995) .

Retinal oximetry is a non-invasive method that can be used to measure the oxygen saturation in retinal vessels, and as a marker for retinal oxygen metabolism (Beach et al. 1999). The method uses a dual-wavelength technique and is based on the principle that the colour of blood depends on the oxygen saturation of haemoglobin. In a systematic review, Rilvén et al reported higher retinal venular oxygen saturation in patients with more advanced levels of DR, potentially identifying retinal oximetry as tool for screening or a biomarker of treatment outcome in patients with ischaemic retinal diseases (Rilven et al. 2017). In a group of young patients with type 1 diabetes, Veiby et al demonstrated retinal metabolic alterations in the early stages of DR (Veiby et al. 2020), but in older patients, it is not known if this increment happens gradually along the DR-spectrum, or if it is triggered at a certain level of structural damage in the retinal microvasculature.

The retinal microvasculature has traditionally been visualized by fluorescein angiography, but this is an invasive, time consuming procedure with potential side effects, which makes it unsuitable as a biomarker of treatment outcome. Hence, it is predominantly used in patients with suspected sight-threatening disease. Optical coherence tomography angiography (OCTA) is a novel, non-invasive method to visualize the retinal microvasculature. Motion-contrast images are used to image high-resolution blood flow in order to generate angiographic images in a matter of seconds. OCTA enables clinicians, for the first time, to visualize the separate layers of the retinal microvasculature, which have previously only been visible with histological examinations (Figure 1) (Dimitrova et al. 2017; Ting et al. 2017). To quantify central retinal ischaemia and remodelling, a variety of quantitative metrics can be obtained from OCTA, including different matrices of the foveal avascular zone (FAZ) dimensions, a circularity index (FAZ circularity), vessel density (VD), fractal dimension (FD), and vessel diameter index (VDI) (Tang et al. 2017). However, there is a paucity of data examining how retinal microvasculature is influenced by retinal oxygen metabolism. 
Therefore, the aim of the present study was to identify at which stages metabolic and microstructural changes occurred in DR and to explore potential associations between the corresponding non-invasive retinal markers.

\section{Methods}

\section{Cohort and recruitment}

Patients were recruited from the Funen Diabetes Database (FDDB), which was established in 2003 on the island of Funen, Denmark, which has approximately 473,000 inhabitants (2018). The FDDB contains data of over 22,000 patients with diabetes (Larsen et al. 2017). It is continuously updated on an individual level and contains information of age, sex, type and duration of diabetes, glycaemic regulation, blood pressure, body mass index and levels of microvascular complications including level of DR.

All patients registered in the FDDB had their retinal fundus images graded by trained ophthalmic graders and the results were entered onto the relevant section of FDDB. For the current study, patients identified in FDDB with valid grading of DR (using the International Clinical Diabetic Retinopathy (ICDR) severity scale)(Wilkinson et al. 2003) were invited to participate. Patients were approached by a standard letter, and if they indicated their willingness to participate in the study, a mutually agreeable time was found for detailed examination and imaging that took place at the Department of Ophthalmology, Odense University Hospital, Odense, Denmark. Altogether, we included 100 patients with diabetes with equal distribution of the severity of DR from no DR to severe nonproliferative DR (NPDR) in at least one eye as per last screening episode. Eyes treated with panretinal photocoagulation for PDR were not included in the study.

\section{Examination}

All eyes were dilated using one drop of tropicamide 1\%. For retinal oximetry, optic disc-centred fundus images were captured by the Oxymap model T1 (Oxymap, Reykjavik, Iceland) using a standard protocol as specified by the manufacturer. Two-field (optic disc and macula centred) 45-degrees colour fundus images and fovea-centred $4.5 \times 4.5 \mathrm{~mm}$ OCTA images were taken by Topcon DRI OCT Triton (Topcon, Tokyo, Japan).

\section{Image Analysis}

All colour fundus images were graded using the ICDR severity scale by the single, certified grader (GW) at the Belfast Reading Centre, Queen's University, Royal Victoria Hospital, Belfast, Northern Ireland, UK. Categories included no DR (level 0), mild NPDR (level 1), moderate NPDR (level 2) and severe NPDR (level 3) (Wilkinson et al. 2003). Finally, PDR was categorized as level 4, classified by the presence of neovascularisation and/or vitreous or pre-retinal haemorrhage. 
The retinal arteriolar and venular oxygen saturation $\left(\mathrm{raSatO}_{2}\right.$ and $\left.\mathrm{rvSatO}_{2}\right)$ was determined by retinal oximetry in larger retinal arterioles and venules, measured around the optic disc by the Oxymap T1 using the Oxymap Analyzer software. A two-wavelength technique was used to estimate the oxygen saturation of haemoglobin (Beach et al. 1999), and a colour map delineated the oxygen saturation of the retinal vessels (Figure 2) (Stefansson et al. 2019). The equipment and technique for retinal oximetry have previously been described in detail (Geirsdottir et al. 2012). All images were graded by a single trained grader (GW) according to a pre-specified protocol. The oximetry measurements were performed between two semi-automatically placed rings, around the optic disc. The first, inner ring was manually placed between 20 and 30 pixels from the edge of the optic disc and the second, outer ring was automatically placed at three times the diameter of the inner ring (Torp et al. 2017). The largest retinal arteriole and venule in each quadrant were manually traced at a length of 50150 pixels and oxygen saturations are presented as the average saturation of the four traced arterioles $\left(\mathrm{raSatO}_{2}\right)$ and venules $\left(\mathrm{rvSatO}_{2}\right)$, respectively.

The OCTA images were analysed by an automated software, measuring the size of the FAZ, VD, FD, VDI and the circularity of the FAZ of the superficial and deep retinal vascular plexus according to a pre-specified protocol (Tang et al. 2017). All OCTA images were analysed at the Department of Ophthalmology and Visual Sciences, The Chinese University of Hong Kong, Hong Kong, China.

\section{Ethical aspects:}

This study was carried out in accordance with the Declaration of Helsinki and good Clinical Practice. Written informed consent was obtained from all patients after thorough written and oral information about the course and possible consequences of the study. Approval for this study was obtained from the FDDB board committee, and ethical approval was obtained from the Regional Scientific Ethical Committee of Southern Denmark.

\section{Statistical analysis}

Stata Intercooled 15.1 (StataCorp, College Station, Texas) was used for all statistical analyses in this study. Continuous data are presented as mean (with 95\% confidence intervals) and categorical data as percentages. Differences or trends across DR severity and, respectively, retinal oxygen saturation, FAZ size, VD, VDI, FD and FAZ circularity were tested employing cluster robust standard errors for linear regression models, as patients were allowed to participate with both eyes. $\mathrm{Chi}^{2}$ test was used for comparison of proportions.

All statistical differences were tested at the 0.05 level, and confidence intervals that did not cross 1.0 were considered statistically significant. 


\section{Results}

One hundred ninety-nine eyes of 100 patients were examined (one eye of one patient could not be examined due to anophthalmia). Four eyes were known to have PDR at the time of last screening and therefore were ineligible for the study. Forty-five eyes were excluded due to poor image quality, and 11 eyes had progressed to PDR since the last screening episode, or had not been updated accordingly in the FDDB. These eyes were, consequently, also excluded from the study. This led to a final inclusion of 139 eyes of 80 patients.

The overall characteristics of the included participants are shown in Table 1. Among the included eyes were 49 (35.3\%) eyes with no DR, 29 (20.9\%) eyes with mild NPDR, 40 (28.8\%) eyes with moderate NPDR, and 21 (15.1\%) eyes with severe NPDR. Additional data for the participants included type of diabetes, HbA1c, and body mass index (BMI). A statistical significant difference amongst the four groups was identified for duration of diabetes for moderate NPDR compared to no DR (25.6 years vs. 18.1 years, $\mathrm{p}=0.02$, linear regression model employing cluster robust standard errors), HbA1c for severe NPDR compared to mild NPDR ( $89.1 \mathrm{mmol} / \mathrm{mol}$ vs. $73.8 \mathrm{mmol} / \mathrm{mol}, \mathrm{p}=0.02)$, and retinal oximetry image quality for severe NPDR compared to no, mild and moderate NPDR (7.9 vs 7.4, 7.3 and 7.3, p=0.03).

Metabolic and structural results are presented in Table 2. The overall raSatO ${ }_{2}$ and $\mathrm{rvSatO}_{2}$ were $90.7 \pm 1.1 \%$ and $50.9 \pm 1.5 \%$. RvSatO ${ }_{2}$ increased with increasing level of $\mathrm{DR}(\mathrm{p}=0.02)$. Eyes with severe NPDR $(59.8 \pm 3.1 \%)$ had a higher rvSatO $_{2}$ as compared to eyes with no DR $(51.3 \pm 1.6 \%)$, mild NPDR $(53.3 \pm 1.9 \%)$ and moderate NPDR $(54.2 \pm 2.4)$. There was no association between $\mathrm{raSatO}_{2}$ and severity of DR ( $\mathrm{p}=0.48)$. There was a tendency towards a decreased arteriolar-venular difference with increasing levels of DR $(\mathrm{p}=0.08)$.

The overall FAZ size of the superficial and deep capillary plexus was $0.345 \pm 0.024 \mathrm{~mm}^{2}$ and $1.277 \pm 0.172 \mathrm{~mm}^{2}$. These did not associate with level of $D R(p=0.36$ and $p=0.60)$. Likewise, no correlations were found between superficial or deep $\mathrm{FAZ}$ size and $\mathrm{raSatO}_{2}$ and $\mathrm{rvSatO}_{2}$ (superficial FAZ: $\mathrm{p}=0.90$ and $\mathrm{p}=0.76$, deep FAZ: $\mathrm{p}=0.50$ and $\mathrm{p}=0.21$, for $\mathrm{raSatO}_{2}$ and $\mathrm{rvSatO}_{2}$ respectively) (Table 3).

The overall VD, VDI, FD and FAZ circularity were $0.696 \pm 0.009 \%, 0.0165 \pm 0.0002 \mathrm{~mm}$, $1.695 \pm 0.002$ and $0.644 \pm 0.019$ at the superficial capillary plexus, and $0.387 \pm 0.006 \%, 0.0146 \pm 0.0013$ $\mathrm{mm}, 1.691 \pm 0.003$ and $0.444 \pm 0.016$ at the deep capillary plexus, respectively. A trend was identified for decreasing VD, increasing VDI, decreasing FAZ circularity at the superficial capillary plexus across ICDR levels $0-3(p<0.001, p=0.0033$ and 0.006), and, likewise, for decreasing FD at the superficial and deep capillary plexus (ICDR level 0-3: 1.695, 1.691, 1.685, 1.681, $\mathrm{p}<0.001$, and 1.691, 1.691, 1.678, 1.683, $\mathrm{p}=0.014$ ). No trend was found regarding VD, VDI or FAZ circularity across ICDR levels 0-3 ( $\mathrm{p}=0.092$, $\mathrm{p}=0.76$ and $\mathrm{p}=0.48$, respectively) at the deep capillary plexus.

A correlation was identified between raSatO $_{2}$ and VDI $(\mathrm{p}<0.01)$ and likewise between $\mathrm{rvSatO}_{2}$ and VDI $(\mathrm{p}<0.01)$, at the deep capillary plexus. No correlations were found between $\mathrm{raSatO}_{2}$ or 
rvSatO $_{2}$ and VD, FAZ circularity and FD at the superficial or deep capillary plexus. Likewise, no correlation was found between raSatO $\mathrm{O}_{2}$ or $\mathrm{rvSatO}_{2}$ and VDI at the superficial capillary plexus (Table 3).

\section{Discussion}

In the present study, we examined the connection between retinal metabolic and structural alterations in eyes with increasing severity of DR. Trends for increasing venular retinal vascular metabolism and retinal structural changes were found along the DR-spectrum, but the sparse correlations between metabolic and structural abnormalities indicates that these changes occur independently.

In a systematic review, Rilvén et al examined associations between retinal oxygen saturation and retinal ischaemic diseases, and concluded that in patients with diabetes increasing $\mathrm{rvSatO}_{2}$ was associated with increasing levels of DR (Rilven et al. 2017). In the present study, we similarly report significant associations between retinal venular oxygen saturation and DR severity, identifying a trend of increasing $\mathrm{rvSatO}_{2}$ with increasing levels of NPDR. This indicates lower retinal oxygen consumption in eyes with more advanced stages of DR. In contrast, we did not observe differences in retinal arteriolar oxygen saturations between DR-groups. The reason for this discrepancy may be the fact that the retinal arteriolar oxygen saturation, as opposed to the retinal venular oxygen saturation, does not depend upon the retinal oxygen consumption.

FAZ size did not associate with level of DR in the present study. De Carlo et al. prospectively evaluated OCTA images of 61 eyes of patients with diabetes and 28 control eyes of healthy subjects with regards to FAZ size, irregularity, vessel beading and tortuosity, capillary non-perfusion and microaneurysms (de Carlo et al. 2015). In that study, FAZ size was increased in eyes of patients with diabetes as compared to eyes of healthy controls $\left(0.35 \mathrm{~mm}^{2}\right.$ vs. $\left.0.29 \mathrm{~mm}^{2}, \mathrm{p}=0.04\right)$. Likewise, Dimitrova et al found an increased superficial FAZ size in patients with diabetes $\left(0.37 \mathrm{~mm}^{2}\right)$ in comparison to healthy controls $\left(0.31 \mathrm{~mm}^{2}\right)$ (Dimitrova et al. 2017). This current study found no such trend, which might be explained by the small patient cohort, the lack of a healthy control group, or that potential changes in FAZ size does not concur with the ICDR levels tested. It was noted that size of FAZ varies among individuals and thus it is not easy to assess possible pathologic FAZ enlargement in the setting of retinal diseases (Mammo et al. 2015; Tang et al. 2017).

In this study, a trend for decreasing VD, increasing VDI and decreasing FAZ circularity were identified at the superficial capillary plexus across ICDR levels, while a trend for decreasing FD was observed at both superficial and deep capillary plexus, indicating increasing microvascular damage with increasing DR severity. Similar results were found by Tang et al, who found that increasing DR severity was associated with increased FAZ area, decreased FAZ circularity, lower VD, lower FD and increased VDI (Tang et al. 2017). These matrices were chosen specifically, as previous studies had identified correlations between increased FAZ area and shorter axial length and thinner central subfield 
macular thickness. Statistically significant correlations were also found between decreased FAZ circularity and visual function, decreased VD and thinner ganglion-cell inner plexiform layer, lower FD and increased DR-severity and increased VDI and higher fasting glucose levels. Therefore, it has been suggested that the extent of microvascular damage can be quantified from OCTA (Tang et al. 2017).

In our study, no correlations were found when comparing the superficial and deep FAZ sizes, VD, FAZ circularity and FD to raSatO ${ }_{2}$ and $\mathrm{rvSatO}_{2}$ within the levels of DR severity (data not presented). This might not be such a surprise, as the OCTA images evaluate the superficial and deep capillary plexus with a $4.5 \mathrm{~mm}$ x $4.5 \mathrm{~mm}$ field in the central macular area. In contrast, retinal oximetry is based on fundus images and hence, a more uniform field of view would have been preferred and may readily become possible as the technology of OCTA develops for wide-field imaging. However, a correlation was identified, when comparing $\mathrm{raSatO}_{2}$ and $\mathrm{rvSatO}_{2}$ to VDI at the deep capillary plexus. The discrepancy between the fact that microvascular structural alteration were observed throughout the DR-spectrum in the superficial capillary plexus, but that the metabolic-structural connection occurred in the deep capillary plexus is intriguing. It may indicate that the deeper part of the retinal vascular tree plays a bigger role in retinal metabolism.

Strengths of the present study include the use of a well-characterised population of patients with diabetes with representation of all degrees of severity of NPDR. However, the findings from our study should be interpreted with caution, given its cross-sectional design and the limited number of patients. Also, the differences in age and duration between included and excluded patients may have influenced our results.

In conclusion, the present study found few correlations between retinal metabolic and microvascular structural alterations, indicating that metabolic and structural abnormalities may occur independently at increasing DR-stages. Furthermore, it demonstrates trends for increased microvascular structural changes and venular retinal metabolic alterations throughout the spectrum of DR. If confirmed by prospective data, this could confirm retinal oximetry as an easily accessible, noninvasive retinal risk factor of DR progression. Such observations would imply that retinal oximetry could be used in adjunct to level of DR and OCTA imaging to identify patients at risk of PDR in diabetic eye screening.

\section{Acknowledgements}

This research was supported by Odense University Hospital grant for pre-graduate projects, University of Southern Denmark grant for internationalization, the A. P. Møller Foundation for the Advancement of Medical Science, and OPEN, Open Patient data Explorative Network, Odense University Hospital, Odense, Denmark. Additional support was given by the Belfast Reading Centre, operating under the 
Central Angiographic Resource Facility, Queen's University Belfast and the Royal Victoria Hospital, where substantial parts of the research were conducted. 


\section{References}

(1995): The relationship of glycemic exposure (HbA1c) to the risk of development and progression of retinopathy in the diabetes control and complications trial. Diabetes 44: 968-983.

(2018): http://www.dst.dk/da/Statistik/kommunekort/kommunefakta. .

Aspelund T, O Thornorisdottir, E Olafsdottir, A Gudmundsdottir, AB Einarsdottir, J Mehlsen, S Einarsson, 0 Palsson, G Einarsson, T Bek \& E Stefansson (2011): Individual risk assessment and information technology to optimise screening frequency for diabetic retinopathy. Diabetologia 54: $2525-2532$.

Beach JM, KJ Schwenzer, S Srinivas, D Kim \& JS Tiedeman (1999): Oximetry of retinal vessels by dualwavelength imaging: calibration and influence of pigmentation. J Appl Physiol (1985) 86: 748758.

de Carlo TE, AT Chin, MA Bonini Filho, M Adhi, L Branchini, DA Salz, CR Baumal, C Crawford, E Reichel, AJ Witkin, JS Duker \& NK Waheed (2015): Detection of Microvascular Changes in Eyes of Patients with Diabetes but Not Clinical Diabetic Retinopathy Using Optical Coherence Tomography Angiography. Retina 35: 2364-2370.

Dimitrova G, E Chihara, H Takahashi, H Amano \& K Okazaki (2017): Quantitative Retinal Optical Coherence Tomography Angiography in Patients With Diabetes Without Diabetic Retinopathy. Invest Ophthalmol Vis Sci 58: 190-196.

Geirsdottir A, O Palsson, SH Hardarson, OB Olafsdottir, JV Kristjansdottir \& E Stefansson (2012): Retinal vessel oxygen saturation in healthy individuals. Invest Ophthalmol Vis Sci 53: 5433-5442.

Larsen MB, JE Henriksen, J Grauslund \& T Peto (2017): Prevalence and risk factors for diabetic retinopathy in 17152 patients from the island of Funen, Denmark. Acta ophthalmologica 95: 778-786.

Liesenfeld B, E Kohner, W Piehlmeier, S Kluthe, S Aldington, M Porta, T Bek, M Obermaier, H Mayer, G Mann, R Holle \& KD Hepp (2000): A telemedical approach to the screening of diabetic retinopathy: digital fundus photography. Diabetes Care 23: 345-348. 
Mammo Z, C Balaratnasingam, P Yu, J Xu, M Heisler, P Mackenzie, A Merkur, A Kirker, D Albiani, KB Freund, MV Sarunic \& DY Yu (2015): Quantitative Noninvasive Angiography of the Fovea Centralis Using Speckle Variance Optical Coherence Tomography. Invest Ophthalmol Vis Sci 56: 5074-5086.

Peters AL, MB Davidson \& FH Ziel (1993): Cost-effective screening for diabetic retinopathy using a nonmydriatic retinal camera in a prepaid health-care setting. Diabetes Care 16: 1193-1195.

Prokofyeva E \& E Zrenner (2012): Epidemiology of major eye diseases leading to blindness in Europe: a literature review. Ophthalmic Res 47: 171-188.

Rilven S, TL Torp \& J Grauslund (2017): Retinal oximetry in patients with ischaemic retinal diseases. Acta ophthalmologica 95: 119-127.

Stefansson E, OB Olafsdottir, TS Eliasdottir, W Vehmeijer, AB Einarsdottir, T Bek, TL Torp, J Grauslund, T Eysteinsson, RA Karlsson, K Van Keer, I Stalmans, E Vandewalle, MG Todorova, M Hammer, G Garhofer, L Schmetterer, M Sin \& SH Hardarson (2019): Retinal oximetry: Metabolic imaging for diseases of the retina and brain. Prog Retin Eye Res.

Tang FY, DS Ng, A Lam, F Luk, R Wong, C Chan, S Mohamed, A Fong, J Lok, T Tso, F Lai, M Brelen, TY Wong, CC Tham \& CY Cheung (2017): Determinants of Quantitative Optical Coherence Tomography Angiography Metrics in Patients with Diabetes. Sci Rep 7: 2575.

Ting DS, GS Tan, R Agrawal, Y Yanagi, NM Sie, CW Wong, IY San Yeo, SY Lee, CM Cheung \& TY Wong (2017): Optical Coherence Tomographic Angiography in Type 2 Diabetes and Diabetic Retinopathy. JAMA Ophthalmol.

Torp TL, R Kawasaki, TY Wong, T Peto \& J Grauslund (2017): Changes in retinal venular oxygen saturation predict activity of proliferative diabetic retinopathy 3 months after panretinal photocoagulation. The British journal of ophthalmology.

Veiby NCBB, A Simeunovic, M Heier, C Brunborg, N Saddique, MC Moe, K Dahl-Jorgensen, HD Margeirsdottir \& G Petrovski (2020): Venular oxygen saturation is increased in young patients with type 1 diabetes and mild nonproliferative diabetic retinopathy. Acta ophthalmologica. 
Wilkinson CP, FL Ferris, RE Klein, PP Lee, CD Agardh, M Davis, D Dills, A Kampik, R Pararajasegaram, JT Verdaguer \& GDR Project (2003): Proposed international clinical diabetic retinopathy and diabetic macular edema disease severity scales. Ophthalmology 110: 1677-1682. 


\section{Figure legends}

Figure 1:

Optical coherence tomography angiography metrics of the superficial and deep capillary plexus of a patient with no diabetic retinopathy and a patient with severe non-proliferative diabetic retinopathy.

\section{Figure 2:}

Analysis of optic disc centred retinal oximetry images of a patient with severe (level 3) non-proliferative diabetic retinopathy. 
Table 1: Patient characteristics as stratified by level of diabetic retinopathy according to the International Clinical Diabetic Retinopathy Severity Scale.

\begin{tabular}{|l|c|c|c|c|c|c|}
\hline Characteristics & Level 0 & Level 1 & Level 2 & Level 3 & Total \\
& (49 eyes) & $(29$ eyes) & $(40$ eyes) & P-value & (139 eyes) \\
\hline Age (years) & $58.5 \pm 3.0$ & $60.5 \pm 2.3$ & $60.8 \pm 2.1$ & $54.4 \pm 3.2$ & $59.0 \pm 1.5$ & 0.34 \\
\hline Sex (\% male) & 46.9 & 69.0 & 57.5 & 61.9 & 56.8 & 0.28 \\
\hline Type of diabetes (\% type 1) & 49.0 & 48.3 & 57.5 & 61.9 & 53.2 & 0.68 \\
\hline Duration of diabetes (years) & $18.1 \pm 2.2$ & $21.4 \pm 2.2$ & $25.6 \pm 1.6$ & $22.5 \pm 2.1$ & $21.7 \pm 1.3$ & 0.02 \\
\hline HbA1c (mmol/mol) & $94.5 \pm 8.8$ & $73.8 \pm 2.5$ & $91.3 \pm 8.7$ & $89.1 \pm 3.5$ & $88.0 \pm 4.3$ & 0.02 \\
\hline BMI (kg/m ${ }^{2}$ ) & $28.0 \pm 1.4$ & $31.5 \pm 1.9$ & $29.4 \pm 1.4$ & $29.3 \pm 1.4$ & $29.4 \pm 0.5$ & 0.49 \\
\hline Image quality (Oxymap T1) & $7.4 \pm 0.1$ & $7.3 \pm 0.2$ & $7.3 \pm 0.2$ & $7.9 \pm 0.2$ & $7.4 \pm 0.1$ & 0.03 \\
\hline
\end{tabular}

Continuous data presented as means $\pm \mathrm{SE}$, analysed using linear regression models, employing cluster robust standard errors. Categorical data presented as percent, analysed using Chi ${ }^{2}$ test. 
Table 2: Structural and metabolic retinal measurement as stratified by level of diabetic retinopathy according to the International Clinical Diabetic Retinopathy Severity Scale

\begin{tabular}{|l|l|l|l|l|l|}
\hline \multicolumn{7}{|l|}{} & Level 0 (95\%CI) & Level 1 (95\%CI) & Level 2 (95\%CI) & Level 3 (95\%CI) & P-trend \\
\hline \multicolumn{7}{|l|}{ Retinal vascular oxygen saturation (\%) } \\
\hline Arteriolar & $\begin{array}{l}91.0 \pm 1.3 \\
(88.5-93.5)\end{array}$ & $\begin{array}{l}90.3 \pm 1.2 \\
(87.9-92.8)\end{array}$ & $\begin{array}{l}92.0 \pm 1.2 \\
(87.6-96.3)\end{array}$ & $\begin{array}{l}92.2 \pm 1.2 \\
(89.9-94.5)\end{array}$ & 0.48 \\
\hline Venular & $\begin{array}{l}51.3 \pm 1.6 \\
(48.0-54.6)\end{array}$ & $\begin{array}{l}53.3 \pm 1.9 \\
(49.5-57.0)\end{array}$ & $\begin{array}{l}54.2 \pm 2.4 \\
(49.5-59.0)\end{array}$ & $\begin{array}{l}59.8 \pm 3.1 \\
(53.7-65.9)\end{array}$ & 0.02 \\
\hline \begin{tabular}{l} 
Difference in $\begin{array}{l}3 \text { arteriolar-venular } \\
\text { oxygen saturation }\end{array}$ \\
\hline
\end{tabular} & $39.7 \pm 1.4$ & $\begin{array}{l}37.1 \pm 1.6 \\
(37.5-42.0)\end{array}$ & $\begin{array}{l}37.7 \pm 2.3 \\
(33.2-40.3)\end{array}$ & $\begin{array}{l}32.4 \pm 2.7 \\
(27.1-37.7)\end{array}$ & 0.08 \\
\hline
\end{tabular}

Area of foveal avascular zone $\left(\mathrm{mm}^{2}\right)$

\begin{tabular}{|l|l|l|l|l|l|}
\hline Superficial layer & $0.363 \pm 0.023$ & $0.311 \pm 0.033$ & $0.376 \pm 0.027$ & $0.405 \pm 0.047$ & 0.36 \\
& $(0.318-0.408)$ & $(0.246-0.376)$ & $(0.322-0.430)$ & $(0.310-0.499)$ & \\
\hline \multirow{2}{*}{ Deep layer } & $1.253 \pm 0.176$ & $1.164 \pm 0.221$ & $1.704 \pm 0.271$ & $1.097 \pm 0.197$ & 0.60 \\
\hline
\end{tabular}

Total Vessel Density (\%)

\begin{tabular}{|l|l|l|l|l|l|}
\hline \multirow{2}{*}{ Superficial layer } & $0.695 \pm 0.010$ & $0.674 \pm 0.010$ & $0.650 \pm 0.011$ & $0.623 \pm 0.018$ & $<0.001$ \\
& $(0.675-0.714)$ & $(0.653-0.695)$ & $(0.627-0.673)$ & $(0.587-0.660)$ & \\
\hline \multirow{2}{*}{ Deep layer } & $0.386 \pm 0.006$ & $0.389 \pm 0.006$ & $0.364 \pm 0.005$ & $0.379 \pm 0.010$ & \multirow{2}{*}{0.09} \\
& $(0.374-0.399)$ & $(0.378-0.401)$ & $(0.353-0.374)$ & $(0.358-0.399)$ & \\
\hline
\end{tabular}

Vessel diameter index $(\mathrm{mm})$

\begin{tabular}{|l|l|l|l|l|l|}
\hline Superficial layer & $\begin{array}{l}0.0164 \pm 0.0002 \\
(0.0160-0.0169)\end{array}$ & $\begin{array}{l}0.0169 \pm 0.0003 \\
(0.0163-0.0174)\end{array}$ & $\begin{array}{l}0.0173 \pm 0.0003 \\
(0.0168-0.0178)\end{array}$ & $\begin{array}{l}0.0173 \pm 0.0003 \\
(0.0168-0.0178)\end{array}$ & 0.003 \\
\hline Deep layer & $\begin{array}{l}0.0133 \pm 0.000 \\
1(0.0131-0.0134)\end{array}$ & $\begin{array}{l}0.0186 \pm 0.0052 \\
(0.0082-0.0290)\end{array}$ & $\begin{array}{l}0.0139 \pm 0.0001 \\
(0.0137-0.0142)\end{array}$ & $\begin{array}{l}0.0141 \pm 0.0002 \\
(0.0138-0.0144)\end{array}$ & 0.76 \\
\hline \multicolumn{7}{|l|}{} \\
\hline \multicolumn{7}{|l|}{ Foveal avascular zone circularity } \\
\hline Superficial layer & $\begin{array}{l}0.632 \pm 0.018 \\
(0.596-0.669)\end{array}$ & $\begin{array}{l}0.649 \pm 0.032 \\
(0.585-0.713)\end{array}$ & $\begin{array}{l}0.594 \pm 0.017 \\
(0.559-0.629)\end{array}$ & $\begin{array}{l}0.556 \pm 0.018 \\
(0.520-0.593)\end{array}$ & 0.006 \\
\hline Deep layer & $\begin{array}{l}0.439 \pm 0.016 \\
(0.408-0.470)\end{array}$ & $\begin{array}{l}0.474 \pm 0.027 \\
(0.419-0.528)\end{array}$ & $\begin{array}{l}0.392 \pm 0.018 \\
(0.356-0.429)\end{array}$ & $\begin{array}{l}0.452 \pm 0.028 \\
(0.400-508)\end{array}$ & 0.48 \\
\hline Fractal dimension & \multicolumn{7}{|l}{} & & \\
\hline Superficial layer & $1.695 \pm 0.002$ \\
& $(1.691-1.699)$ & $\begin{array}{l}1.691 \pm 0.002 \\
(1.690-1.194)\end{array}$ & $\begin{array}{l}1.685 \pm 0.002 \\
(1.681-1.689)\end{array}$ & $\begin{array}{l}1.681 \pm 0.003 \\
(1.675-1.687)\end{array}$ & $<0.001$ \\
\hline Deep layer & $\begin{array}{l}1.691 \pm 0.003 \\
(1.685-1.695)\end{array}$ & $\begin{array}{l}1.691 \pm 0.003 \\
(1.686-1.696)\end{array}$ & $\begin{array}{l}1.678 \pm 0.003 \\
(1.672-1.683)\end{array}$ & $\begin{array}{l}1.683 \pm 0.004 \\
(1.674-1.692)\end{array}$ & 0.01 \\
\hline
\end{tabular}


Numbers presented as means $\pm \mathrm{SE}(95 \% \mathrm{CI})$. Levels of diabetic retinopathy (DR): 0 (no DR), 1 (minimal nonproliferative DR [NPDR]), 2 (moderate NPDR) and 3 (severe NPDR). The data in this table was analysed using regression models employing cluster robust standard errors. 
Table 3: Correlations between arteriolar and venular retinal vascular oxygen saturation

\begin{tabular}{|l|c|c|}
\hline & Retinal arteriolar oxygen saturation & Retinal venular oxygen saturation \\
\hline $\begin{array}{l}\text { Area of foveal avascular zone } \\
\text { (superficial layer) }\end{array}$ & 0.90 & 0.76 \\
\hline $\begin{array}{l}\text { Area of foveal avascular zone (deep } \\
\text { layer) }\end{array}$ & 0.50 & 0.21 \\
\hline $\begin{array}{l}\text { Total vessel density } \\
\text { (superficial layer) }\end{array}$ & 0.39 & 0.60 \\
\hline $\begin{array}{l}\text { Total vessel density } \\
\text { (deep layer) }\end{array}$ & 0.49 & 0.52 \\
\hline $\begin{array}{l}\text { Vessel diameter index } \\
\text { (superficial layer) }\end{array}$ & 0.76 & 0.45 \\
\hline $\begin{array}{l}\text { Vessel diameter index } \\
\text { (deep layer) }\end{array}$ & $<0.01$ & $<0.01$ \\
\hline $\begin{array}{l}\text { Foveal avascular zone circularity } \\
\text { (superficial layer) }\end{array}$ & 0.53 & 0.36 \\
\hline $\begin{array}{l}\text { Foveal avascular zone circularity } \\
\text { (deep layer) }\end{array}$ & 0.76 & 0.07 \\
\hline $\begin{array}{l}\text { Fractal dimension } \\
\text { (superficial layer) }\end{array}$ & 0.93 & 0.91 \\
\hline $\begin{array}{l}\text { Fractal dimension } \\
\text { (deep layer) }\end{array}$ & 0.96 \\
\hline
\end{tabular}

Numbers presented as $p$-values. The data in this table was analysed using regression models employing cluster robust standard errors. 
Figure 1

Superficial Layer

No DR

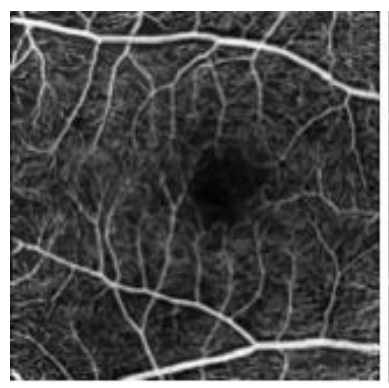

Severe NPDR

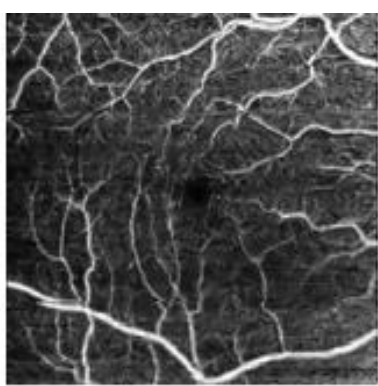

No DR

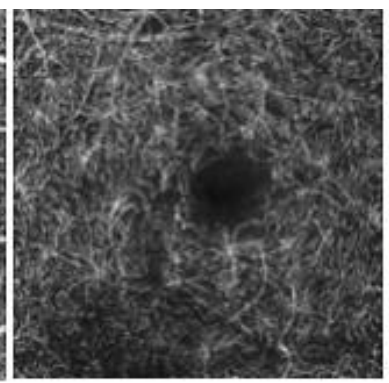

Deep Layer

OCT-A

Binarization
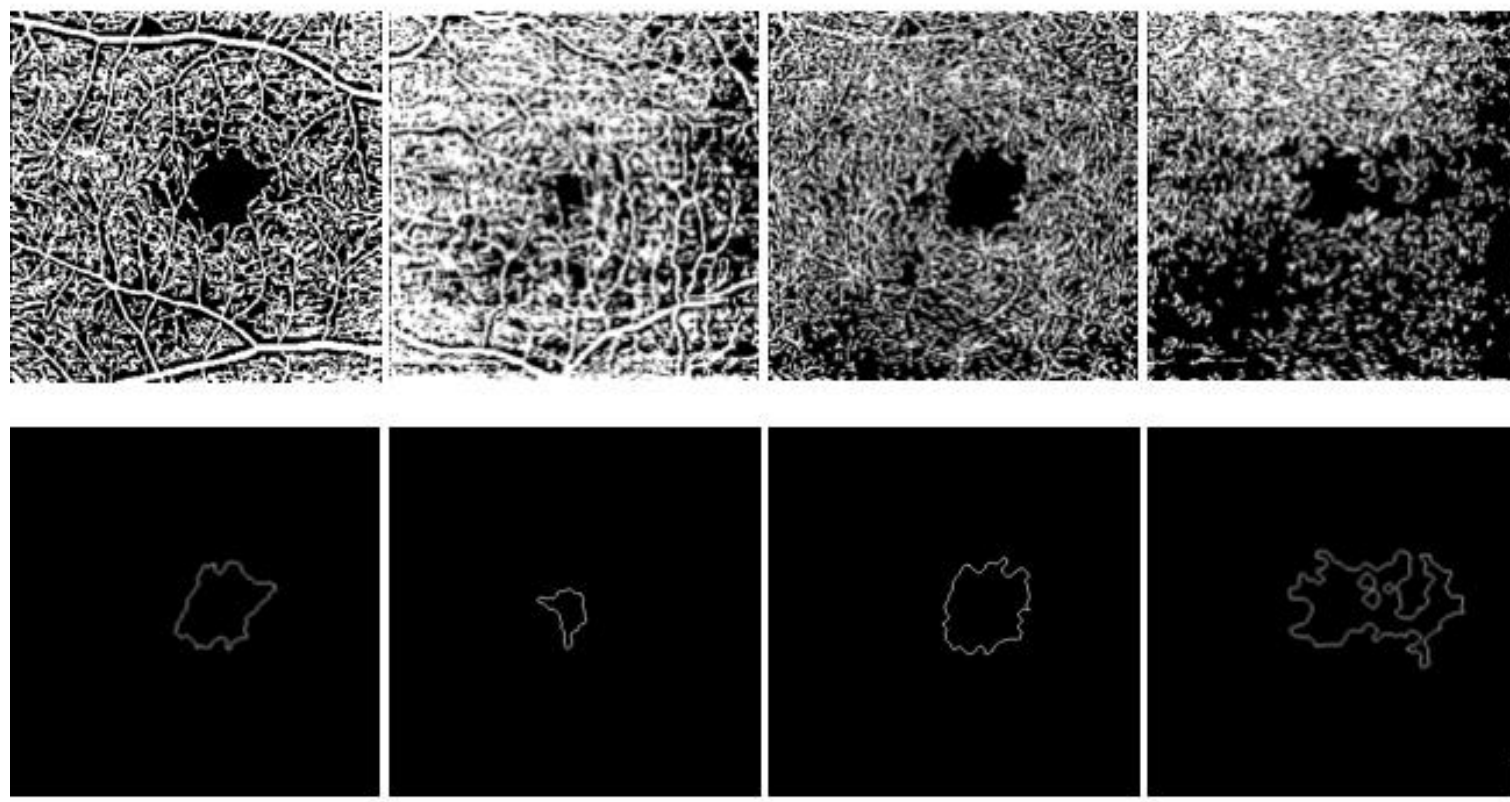

Calculation

of FAZ

circularity

and area

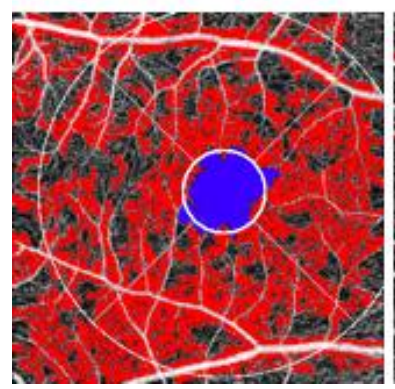

Severe NPDR
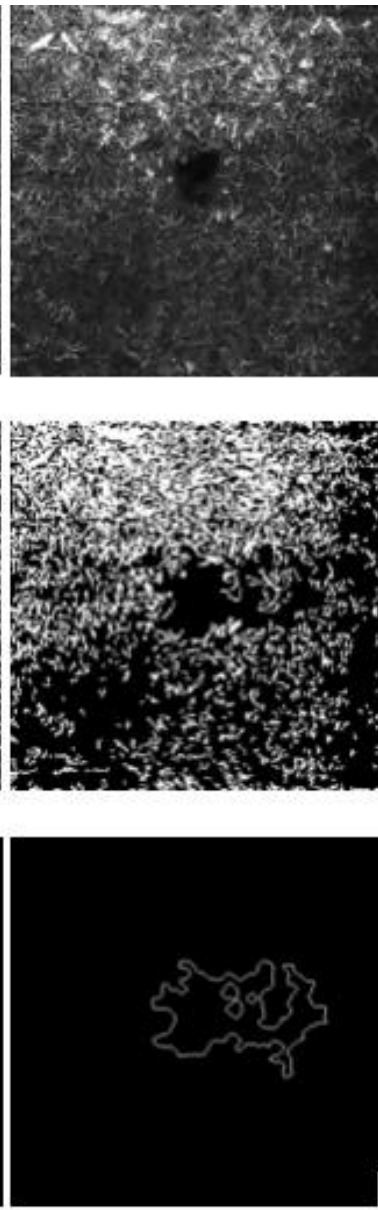

Vessel

density

calculation
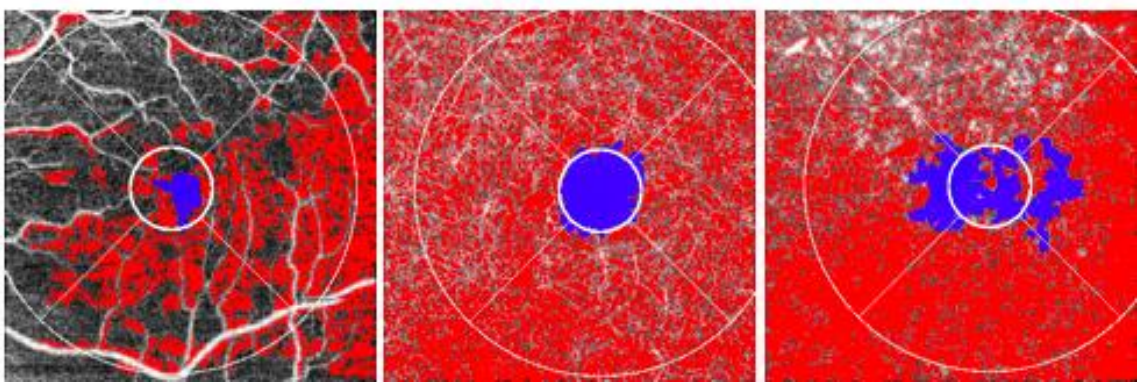


\section{Figure 2}

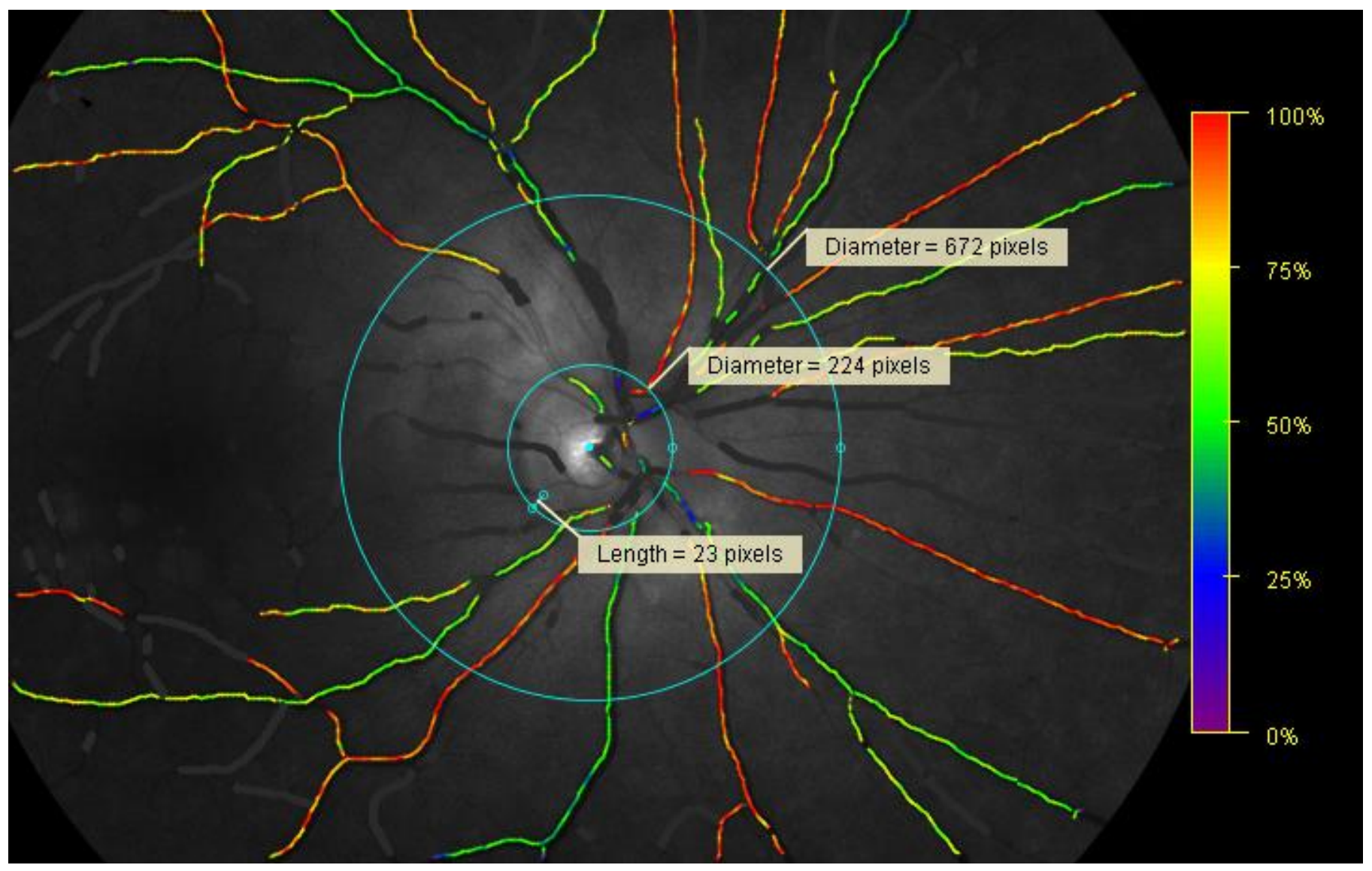

